\title{
COMPETITION IN OR FOR THE FIELD: WHICH IS BETTER?
}

\author{
Eduardo Engel \\ Ronald Fischer \\ Alexander Galetovic \\ Working Paper 8869 \\ http://www.nber.org/papers/w8869
NATIONAL BUREAU OF ECONOMIC RESEARCH
1050 Massachusetts Avenue
Cambridge, MA 02138 \\ April 2002
}

Financial support from FONDE-CYT (Grant 1980658) is gratefully acknowledged. The views expressed herein are those of the authors and not necessarily those of the National Bureau of Economic Research.

(C) 2002 by Eduardo Engel, Ronald Fischer and Alexander Galetovic. All rights reserved. Short sections of text, not to exceed two paragraphs, may be quoted without explicit permission provided that full credit, including (C) notice, is given to the source. 
Competition in or for the Field: Which is Better?

Eduardo Engel, Ronald Fischer and Alexander Galetovic

NBER Working Paper No. 8869

April 2002

JEL No. D44, L12, L92

\begin{abstract}
In many circumstances, a principal, who wants prices to be as low as possible, must contract with agents who would like to charge the monopoly price. This paper compares a Demsetz auction, which awards an exclusive contract to the agent bidding the lowest price (competition for the field) with having two agents provide the good under (imperfectly) competitive conditions (competition in the field). We obtain a simple sufficient condition showing unambiguously which option is best. The condition depends only on the shapes of the surplus function of the principal and the profit function of agents, and is independent of the particular duopoly game played ex post. We apply this condition to three canonical examples - procurement, royalty contracts and dealerships - and find that whenever marginal revenue for the final good is decreasing in the quantity sold, a Demsetz auction is best. Moreover, a planner who wants to maximize social surplus also prefers a Demsetz auction.
\end{abstract}

\author{
Eduardo Engel \\ Department of Economics \\ Yale University \\ 28 Hillhouse Avenue \\ New Haven, CT 06511 \\ and NBER \\ eduardo.engel@yale.edu
}

Ronald Fischer

Center for Applied Economics

Dept. of Industrial Engineering University of Chile

Av. República 701

Santiago, Chile

rfischer@dii.uchile.cl
Alexander Galetovic

Center for Applied Economics

Dept. of Industrial Engineering University of Chile

Av. República 701

Santiago, Chile

agaleto@dii.uchile.cl 


\section{Introduction}

Consider a principal that needs to buy a good or service and has two procurement alternatives. On the one hand, it can award an exclusive contract to the agent offering the lowest price, as in a standard Demsetz (1968) auction. In this case, there will be intense ex ante price competition ('competition for the field'), but in the aftermath, the agent will always charge the maximum price allowed by the contract. The other option is to award two independent supply contracts and rely on ex post competition ('competition in the field'). Then agents will consider the probabilities of different ex post duopoly games when negotiating their contracts. If they anticipate that with high probability there will be intense price competition, they will participate only if they obtain high profits in the rare cases in which they collude. Thus, the prospect of intense competition in the field softens competition for the field. ${ }^{2}$ This motivates the question we address in this paper: Should the principal contract with one or two agents?

The answer does not seem straightforward. A basic difficulty is that the appropriate specification of the ex post duopoly game depends on particular aspects of the situation. ${ }^{3}$ Moreover, many duopoly games have multiple equilibria and there are no a priori compelling reasons to choose one over another. Nevertheless, in this paper we obtain a simple sufficient condition that shows unambiguously which option is better. This condition depends only on the shapes of the surplus function of the principal and the profit function of each agent, and is independent of the duopoly game played ex post. We then apply this condition to study three canonical examples - procurement, royalty contracts and dealerships. We find that whenever marginal revenue is decreasing in the quantities, a Demsetz auction is unambiguously better. Moreover, a planner who wants to maximize social surplus also prefers a Demsetz auction.

Our point of departure is a standard setting where a principal wants the final price of the good or service to be as low as possible, but agents prefer the monopoly price. The principal can either run a Demsetz auction for an exclusive contract, or auction two separate contracts to different agents who then produce perfect substitutes and compete. With a Demsetz auction, the ex post equilibrium price equals the winning bid. By contrast, when there are two contracts, the price depends on the outcome of ex post competition. We do not specify the second stage game, but summarize its outcome as follows: ex ante the equilibrium price is a random variable with an arbitrary distribution $F$ whose support is bounded above by the maximum price allowed by the contract. In some states of nature agents will succeed in colluding and prices will be close to the winning bid; in other states agents will compete intensely and prices will be much lower. ${ }^{4}$

We assume that the principal and the agents are risk neutral. Nevertheless, the main result of the paper exploits the fact that a Demsetz auction eliminates variability in the equilibrium price. To get the intuition

\footnotetext{
${ }^{2}$ This terminology is due to Chadwick (1859).

${ }^{3}$ In this paper we abstract from complications due to incomplete contracting and asymmetric information.

${ }^{4}$ There are several interpretations for $F$. In one of them, it describes agents' uncertainty about ex post market conditions and potential collusive prices. In another, firms always collude at the price that maximizes joint profits, but there is a positive probability of a successful antitrust case against them, leading to a price equal to marginal costs. Similarly, in the specific case of dealerships, the upstream firm may try to prevent the double marginalization associated with collusion by penalizing those agreements between franchisors that are detected.
} 
in a simple setting, assume that the agents' profits, $\pi$, are increasing and concave in the equilibrium price, and that the principal's surplus function, $\mathcal{S}$, is decreasing and linear in the equilibrium price. ${ }^{5}$ Consider next what happens if the principal substitutes two independent contracts by a Demsetz auction. Clearly, this eliminates the price variability described by $F$. And since $\pi$ is concave in price and the participation constraint always binds, the price that results from a Demsetz auction must be lower than the average with two agents and ex post competition, i.e., competition for the field leads to lower prices than competition in the field. Thus, a Demsetz auction is better for the principal when her surplus function is linear. It is easily seen, as well, that if the surplus function $\mathcal{S}$ is sufficiently convex, separate contracts may be better, because then the principal likes price variability. Our main result generalizes this intuition and shows that a Demsetz auction is unambiguously better when the composition of the principal's surplus function and the inverse profit function, $\mathcal{S} \circ \pi^{-1}$, is strictly concave. Conversely, when this composite function is strictly convex two separate contracts are unambiguously better.

As in the theory of expected utility, we find that this general result is equivalent to a simple condition that compares the curvatures of the surplus and profit functions. This condition is quite similar to the necessary and sufficient condition for a utility function to be more risk averse than the other (Pratt's [1964] theorem) and makes it easier to compare competition in the field with competition for the field. The condition amounts to checking a relation that involves only the first and second derivatives of $\mathcal{S}$ and $\pi$. We illustrate the usefulness of this condition in the applications section, showing that a Demsetz auction is preferred by the principal in all cases considered-procurement, royalty contracts, dealerships-whenever marginal profits are decreasing in quantities.

Our paper is related to the literature of monopoly regulation via franchising which was pioneered by Chadwick (1859) and Demsetz (1968) (see also Stigler [1968], Posner [1972], Williamson [1975], Riordan and Sappington [1987], Spulber [1989, ch. 9], Laffont and Tirole [1993, chs. 7 and 8], Harstad and Crew [1999] and Engel, Fischer and Galetovic [2001 a, b]). We extend this literature by studying Demsetz auctions in contexts where imperfect competition "in the field" is feasible and is an alternative to a standard Demsetz auction.

The applications we study suggest that our paper is also related to the literature on the "double marginalization" problem in monopoly pricing (see Spengler [1950] for the seminal contribution and Tirole [1988, ch. 4] for a review of the literature). Our result implies that when marginal revenue is decreasing in the quantity sold and downstream competition is imperfect, auctioning an exclusive contract is better than relying on ex post imperfect competition.

The rest of the paper proceeds as follows. In Section 2 we describe the general model and prove the main result of the paper. In section 3 we apply this general result to study four applications. Section 4 concludes

\footnotetext{
${ }^{5}$ While we assume that profit and surplus functions are linear in money (that is, they are risk neutral in money terms), neither the agents' profit function nor the principal's surplus function need, in general, be linear in the equilibrium price, i.e., they are risk averse (or loving) in prices. For example, profit functions are typically quasiconcave in price. By contrast, when the agent is a planner who wants to maximize consumer surplus, the principal's objective function is convex in prices.
} 
and is followed by a brief appendix.

\section{General model and main result}

A risk neutral principal wants to contract the production of a good at two plants or locations. ${ }^{6}$ Output from one plant is a perfect substitute for the output of the other. If the equilibrium price is $p$, an agent producing at one plant makes profits $\pi(p)$, with $\pi^{\prime}(p)>0$ for $p \in\left[\underline{p}, p_{m}\right)$, where $\pi(\underline{p})=0$ and $p_{m}=\arg \max _{p} \pi(p)$. Furthermore, $\pi^{\prime}\left(p_{m}\right)=0$ and $\pi^{\prime \prime}\left(p_{m}\right)<0$. On the other hand, the principal's surplus is $\mathcal{S}(p)$ if agents charge $p$, with $\mathcal{S}^{\prime}(p)<0$. Hence there is a conflict of interest: while agents would like to increase prices up to $p_{m}$, the principal wants the price to be as low as possible.

The principal may award both plants jointly $(J)$, so that they are run by one agent; or separately $(S)$, so that two agents run one plant each and compete. The principal auctions both contracts. When both plants are awarded jointly, the winning bid is denoted by $p_{J}$ and per-plant profits for the agent are equal to $\pi\left(p_{J}\right){ }^{7}$ On the other hand, when plants are awarded to different agents, the minimum winning bid, common across plants, is denoted by $p_{S}$. In this case agents are uncertain both about whether they will be able to collude, ${ }^{8}$ and, if they do, about the price above $p$ at which they will collude. ${ }^{9}$ We assume that each agent serves half the demand at a common equilibrium price $p$, and denote by $F(p)$ the cdf with support $\left[\underline{p}, p_{S}\right]$ that describes their common beliefs about the realization of this price. ${ }^{10}$

We make the essential assumption that ex-ante expected gross profits per plant under a joint or a separate auction are the same, that is

\section{Condition 1}

$$
\int_{\underline{p}}^{p_{S}} \pi(p) d F(p)=\pi\left(p_{J}\right)=\bar{u}+I
$$

where $\bar{u}$ is the agent's reservation utility and I stands for any sunk setup cost. There exist many agents that could produce the good, all of them with the same value of $(\bar{u}+I)$.

Condition 1 implies that benefits for agents are independent of whether the principal auctions production at both plants jointly or separately. Or, in the standard guise of principal-agent theory, Condition 1 is the participation constraint that the principal must obey. Note also that if $F(p)$ is degenerate, Condition 1 implies that under separate auctions the price will be $p_{J}$, so that joint and separate auctions are identical. We rule out this possibility by assumption in what follows.

\footnotetext{
${ }^{6}$ All that follows extends trivially to the case of $n$ locations.

${ }^{7}$ We assume $p_{J} \leq p_{m}$.

${ }^{8}$ Caillaud and Tirole (2001) consider this possibility in the context of essential facilities.

${ }^{9}$ That is, we assume that prices are such that agents do not lose money ex post, since $\pi(p)=0$.

${ }^{10}$ Competition in practice is generally neither static nor symmetric. We avoid complications by concentrating on stationary equilibria and we use symmetry due to the lack of consensus on how to model collusion in asymmetric games.
} 
When plants are awarded jointly, the principal's benefit is denoted $W_{J} \equiv \mathcal{S}\left(p_{J}\right)$. On the other hand, when when they are awarded separately, the principal's expected benefit depends on the distribution of collusive prices $F$ and equals

$$
W_{S} \equiv \int_{\underline{p}}^{p_{S}} \mathcal{S}(p) d F(p) .
$$

From the assumptions we made on $\pi$, it follows that $\pi^{-1}:\left[\pi(\underline{p}), \pi\left(p_{m}\right)\right] \rightarrow\left[\underline{p}, p_{m}\right]$ is well defined, increasing and convex. We then have the following central result of the paper:

Proposition 1 If $\mathcal{S} \circ \pi^{-1}$ is strictly concave, then $W_{J}>W_{S}$. If $\mathcal{S} \circ \pi^{-1}$ is strictly convex, then $W_{S}>W_{J}$.

Proof: We consider the case where $\mathcal{S} \circ \pi^{-1}$ is concave. The case where it is convex is analogous. We have:

$$
\begin{aligned}
W_{S} & \equiv \int_{\underline{p}}^{p_{S}} \mathcal{S}(p) d F(p) \\
& =\int_{\underline{p}}^{p_{S}} \mathcal{S} \circ \pi^{-1}[\pi(p)] d F(p) \\
& <\mathcal{S} \circ \pi^{-1}\left[\int_{\underline{p}}^{p_{S}} \pi(p) d F(p)\right] \\
& =\mathcal{S} \circ \pi^{-1}\left[\pi\left(p_{J}\right)\right] \\
& =\mathcal{S}\left(p_{J}\right) \\
& \equiv W_{J},
\end{aligned}
$$

where the inequality follows from Jensen's inequality and our assumption that $F$ is not degenerate, and the identity after the inequality from Condition 1.

A surprising feature of this result is that we have not imposed any condition on the distribution of possible collusive outcomes $F$. Hence, in order to compare joint and separate auctions, it is sufficient to examine the 'primitive' functions $\pi$, and $\mathcal{S}$, and one can ignore the exact specification of the ex post game between the agents.

This result depends crucially on Condition 1, which ensures that softer competition when the participation constraint becomes more demanding (that is, $\bar{u}+I$ increases). In the case of joint production, this means softer competition for the franchise, while in the case of separate production it means less competition between both agents after they begin producing.

The following result provides a simple characterization for the concavity of $\mathcal{S} \circ \pi^{-1}$.

Proposition 2 A necessary and sufficient condition for $\mathcal{S} \circ \pi^{-1}$ be concave is that

$$
\frac{S^{\prime \prime}}{S^{\prime}}>\frac{\pi^{\prime \prime}}{\pi^{\prime}}
$$


for all $p \in\left[\underline{p}, p_{m}\right)$. Since, by assumption, $\pi^{\prime}>0$ and $S^{\prime}<0$ in the relevant range, equation (1) is equivalent to

$$
\mathcal{S}^{\prime \prime} \pi^{\prime}<\mathcal{S}^{\prime} \pi^{\prime \prime}
$$

Moreover, the converse of condition (1) is necessary and sufficient for $\mathcal{S} \circ \pi^{-1}$ to be convex.

Proof: See the Appendix.

Corollary 1 If $\pi$ is strictly concave, then the concavity of $\mathcal{S}$ is sufficient for a joint contract to be better than two separate contracts.

We can use Proposition 2 and Figures 1 and 2 to examine the intuition underlying our main result. Suppose that $S$ is linear, $\pi$ strictly concave, two separate contracts are auctioned, and in equilibrium $p$ can take only two values, $p$ and $p_{m}$, with equal probability. In this case each agent makes expected profits equal to $\frac{1}{2} \pi(\underline{p})+\frac{1}{2} \pi\left(p_{m}\right)=\frac{1}{2} \pi\left(p_{m}\right)$ and the principal's surplus equals $\frac{1}{2} \mathcal{S}(\underline{p})+\frac{1}{2} \mathcal{S}\left(p_{m}\right)$ (see Figure 1). Since $\mathcal{S}$ is linear and $\pi$ concave, Proposition 2 holds, and a joint auction is better than a separate auction. Why? Condition 1 implies that $\frac{1}{2} \pi\left(p_{m}\right)=\pi\left(p_{J}\right)$. As is straightforward from Figure 1a, concavity of $\pi$ implies that $p_{J}<\frac{1}{2} \underline{p}+\frac{1}{2} p_{m}$. Hence the principal obtains a lower average price with a joint auction. ${ }^{11}$ Because in this example $\mathcal{S}$ is linear, $\frac{1}{2} S(\underline{p})+\frac{1}{2} S\left(p_{m}\right)=S\left(\frac{1}{2} \underline{p}+\frac{1}{2} p_{m}\right)<\mathcal{S}\left(p_{J}\right)$ (see Figure 1b). Note that the same reasoning applies to any probability distribution $F$ with support in the interval $\left[\underline{p}, p_{m}\right]$.

It can now easily be seen why strict concavity of $\mathcal{S}$ is sufficient for a joint auction to be better when $\pi$ is concave. Eliminating variability in $p$ is an added bonus for the principal, since $\mathrm{E} S(p)<\mathcal{S}(\mathrm{E} p)$ for all distributions $F$. Conversely, when $S$ is convex, a separate auction may (but need not) be better. Figure 2 depicts exactly the same case as Figure 1, except that $S$ is convex, so that now the principal likes price variability. For the particular distribution depicted in this figure, the principal is indifferent between a joint and a separate auction. Essentially, the gain of a lower expected price $p$ attained with a joint auction is exactly offset by the fall in the expected surplus due to lower price variability. With $S$ sufficiently convex and for a given $\pi$, the gains from a lower expected price are outweighed by the utility loss which stems from losing "high" surpluses.

\section{Applications}

In this section we use Proposition 2 to study three canonical applications: procurement (the principal buys the production of the plants), dealerships (agents buy an input from the principal and incur some costs to transform and resell it) and royalties (the principal receives a fixed fee per unit sold by the agent without

\footnotetext{
${ }^{11}$ This can be put in the more standard terms of principal-agent theory. From Condition 1 it follows that the agent's participation constraint is $\frac{1}{2} \pi\left(p_{m}\right)=\pi\left(p_{J}\right)$. Since $\pi$ is concave, the average price that the agent requires in order to participate is lower with a joint contract, which eliminates risk.
} 


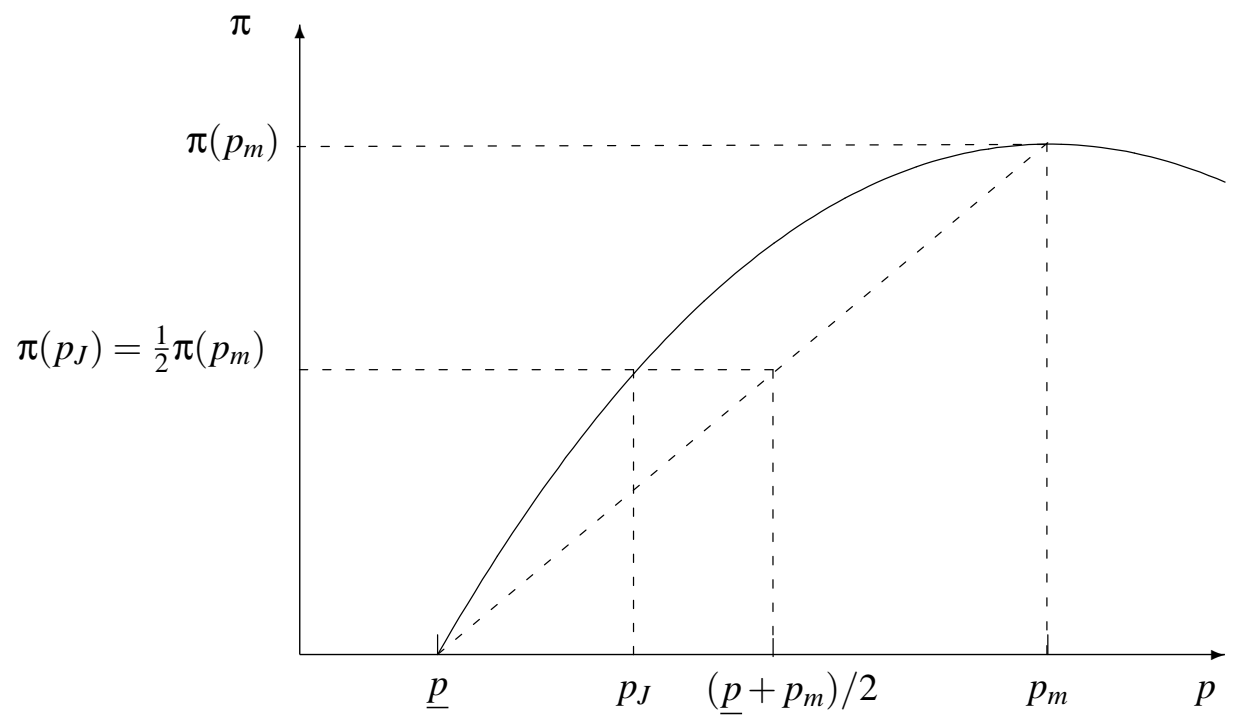

(a)

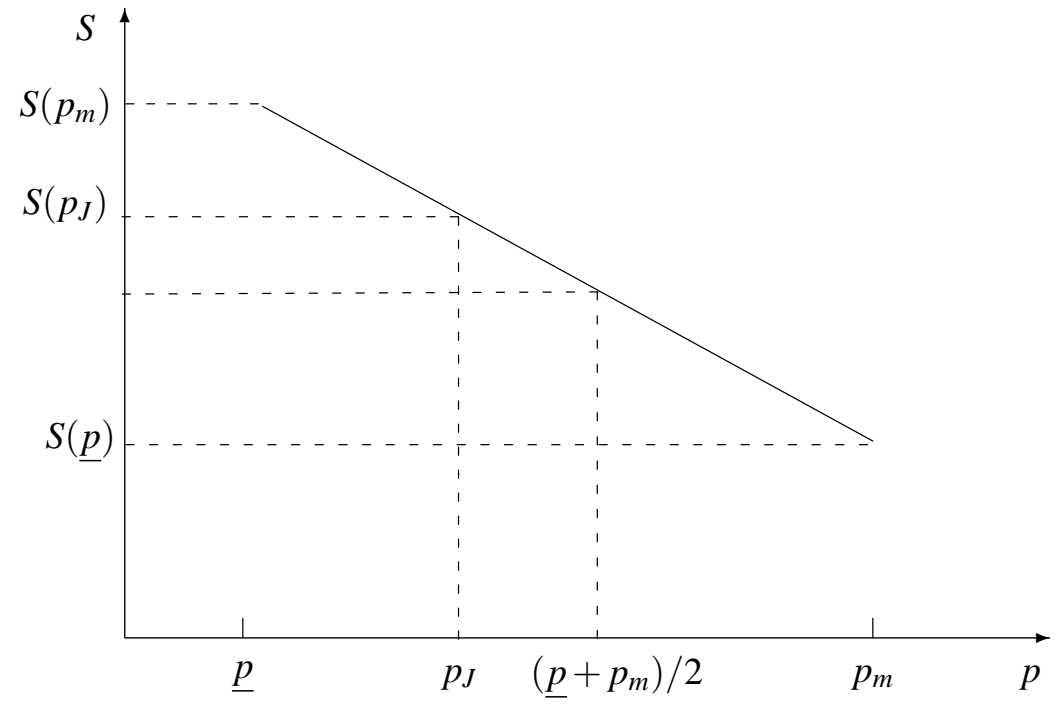

(b)

Figure 1: Intuition underlying the main result: When $\mathcal{S}$ is linear a joint auction is always better. 


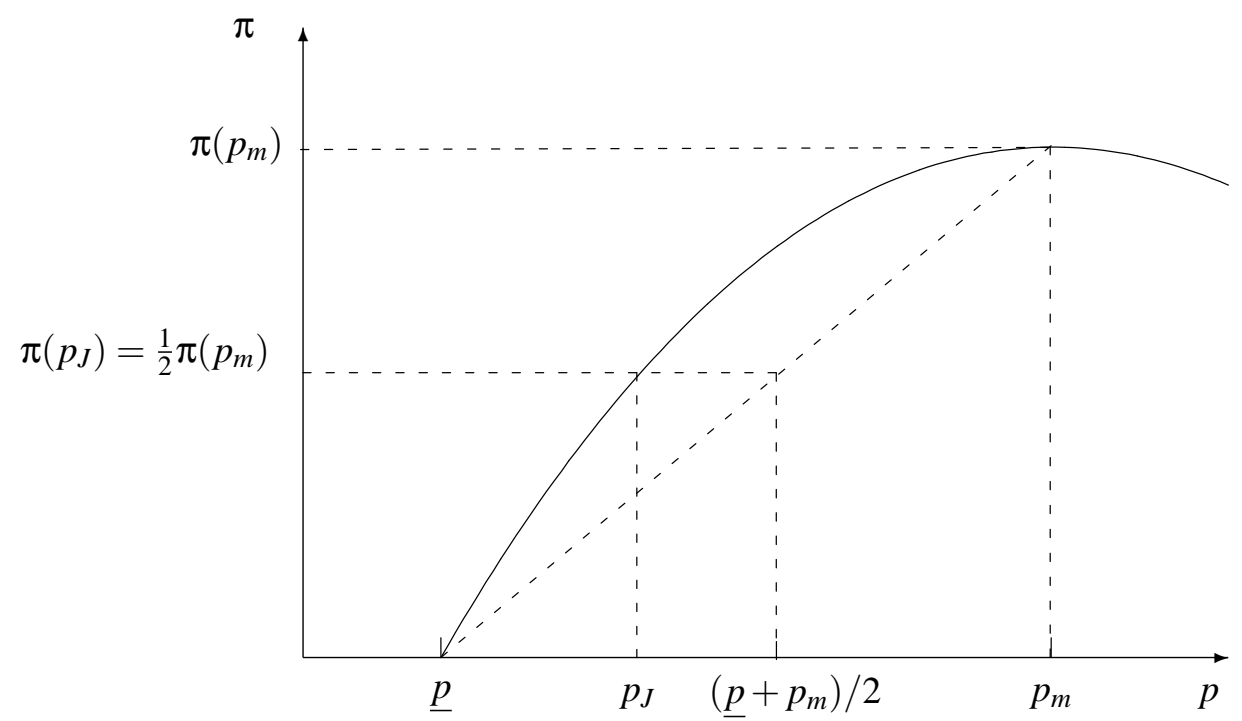

(a)

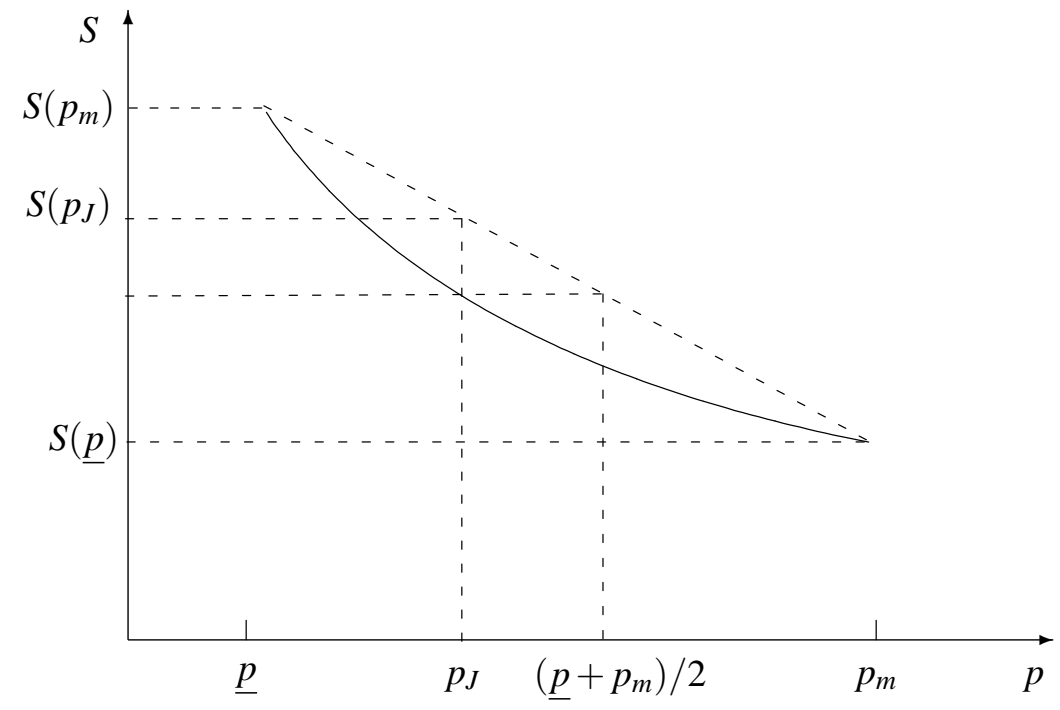

(b)

Figure 2: Intuition underlying the main result: When $\mathcal{S}$ is convex, anything goes. 
engaging in production). In these cases functions $\mathcal{S}$ and $\pi$ can be derived from standard demand and cost functions.

In all the cases that follow we assume that the value of the marginal unit at $q$ is $P(q)$, with $P^{\prime}<0$. We also assume that the inverse function of $P, P^{-1}(p) \equiv D(p)$ is well defined in the appropriate range. Obviously $D^{\prime}<0$. Agent $i$ incurs in total cost $c\left(q_{i}\right)$ when producing $q_{i}$ units of output at a given plant, with $c^{\prime}>0$ and $c^{\prime \prime} \geq 0 .{ }^{12}$

We find that in all three cases a sufficient condition for a joint contract to be better for the principal is that marginal revenue be decreasing in quantities. In addition, we show that whenever this holds, a social planner also prefers a joint auction. The following two lemmas, which are proven in the appendix, will be useful when establishing this result:

Lemma 1 (i) $P^{\prime}(q)=\frac{1}{D^{\prime}(P(q))}$; (ii) $P^{\prime \prime}(q)=-\frac{D^{\prime \prime}(P(q))}{\left\{D^{\prime}(P(q))\right\}^{3}}$; (iii) $D^{\prime}(p)=\frac{1}{P^{\prime}(D(p))} ;($ iv $) D^{\prime \prime}(p)=-\frac{P^{\prime \prime}(D(p))}{\left\{P^{\prime}(D(p))\right\}^{3}}$.

Lemma $22 P^{\prime}(q)+q P^{\prime \prime}(q)<0$ if and only if $D D^{\prime \prime}-2\left(D^{\prime}\right)^{2}<0$.

\subsection{Procurement}

We first consider fixed-price procurement. ${ }^{13}$ The principal wants to buy an input as cheaply as possible, and can choose between one or two suppliers. Clearly, the principal cares (directly) only about the price $p$ paid per unit, and not about production costs $c$ (of course, as in any principal-agent problem, the principal cares about the agents' costs indirectly through the participation constraint). Hence $\mathcal{S}(p) \equiv \int_{p}^{\infty} D(s) d s$ is the principal's surplus, and $\pi(p)=\frac{1}{2} p D(p)-c\left(\frac{D(p)}{2}\right)$ is the surplus of each agent with a separate auction; with a joint auction the agent's surplus is $2 \pi(p)$. In this case $p_{m}=\arg \max \left\{\frac{1}{2} p D(p)-c\left(\frac{D(p)}{2}\right)\right\}$ and $\underline{p}$ is such that $\frac{1}{2} \underline{p} D(\underline{p})-c\left(\frac{D(\underline{p})}{2}\right)=0$. Therefore

$$
\begin{aligned}
& \mathcal{S}^{\prime}=-D<0, \\
& \mathcal{S}^{\prime \prime}=-D^{\prime}>0
\end{aligned}
$$

(i.e. $S$ is convex and Corollary 1 does not apply). Also,

$$
\pi^{\prime}=\frac{1}{2}\left[D+\left(p-c^{\prime}\right) D^{\prime}\right]
$$

\footnotetext{
${ }^{12}$ This condition implies no loss of generality. If $c^{\prime \prime}<0$, marginal and average costs are decreasing and auctioning jointly is clearly better.

${ }^{13}$ In fixed-price procurement contracts, the buyer and the seller agree on a price, and the seller assumes all cost risk. At the other extreme, in a cost-plus contract the buyer reimburses the seller's cost. As argued in Laffont and Tirole (1993, p. 662), only fixed-price contracts are relevant when it is too costly for the buyer to audit the subcost of the supplier.
} 
which we assume strictly positive for $p \in\left[\underline{p}, p_{m}\right)$, and

$$
\pi^{\prime \prime}=\frac{1}{2}\left[\left(p-c^{\prime}\right) D^{\prime \prime}+2 D^{\prime}-\frac{1}{2}\left(D^{\prime}\right)^{2} c^{\prime \prime}\right] .
$$

Applying Propositions 1 and 2 to this case, the following result follows:

Proposition 3 A sufficient condition for $W_{J}>W_{S}$ is that

$$
2 P^{\prime}+q P^{\prime \prime}<0
$$

that is, that marginal revenue be decreasing in $q$.

Proof: Since in the relevant range we have $\mathcal{S}^{\prime}<0$ and $\pi^{\prime}>0$, it follows from Proposition 2 that it suffices to show that (3) ensures that

$$
\mathcal{S}^{\prime \prime} \pi^{\prime}<\mathcal{S}^{\prime} \pi^{\prime \prime}
$$

for all $p \in\left[\underline{p}, p_{m}\right)$. Some straightforward calculations show that (4) is equivalent to:

$$
\left(p-c^{\prime}\right)\left[D^{\prime \prime} D-2\left(D^{\prime}\right)^{2}\right]<-2 \pi^{\prime} D^{\prime}+\frac{1}{2}\left(D^{\prime}\right)^{2} D c^{\prime \prime}
$$

Lemma 2 implies that the left hand side of (5) is negative for all $p \in\left[\underline{p}, p_{m}\right]$ if marginal revenue is decreasing in $q$. On the other hand, the right hand side of (5) is positive, because $c^{\prime \prime} \geq 0$ and $\pi^{\prime}>0$ for all $p \in\left[\underline{p}, p_{m}\right)$.

\subsection{Royalties}

Consider a licensing agreement where the licensee pays the principal a royalty $t$ per unit produced and sold, but no fixed fee. ${ }^{14}$ For example, this is the case when a patent holder licences the right to manufacture the good, but does not participate in the product market. ${ }^{15}$ In this case the principal is worried about downstream double marginalization, and, given $t$, would like the licensee to sell as much as possible. The principal's surplus is $\mathcal{S}(p)=t D(p)$ (where now $D$ is market demand for the good), and $\pi(p)=\frac{1}{2}(p-t) D(p)-c(D(p) / 2)$ is the surplus of each licensee.

We then have that Proposition 3 also applies, i.e. $2 P^{\prime}+q P^{\prime \prime}<0$ is sufficient for $W_{J}>W_{S}$. We postpone the proof until the next subsection.

As is well known, a disadvantage of licensing through royalties is that any market power exercised downstream reduces industry profits (this is the double marginalization problem). One solution is to auction

\footnotetext{
${ }^{14}$ Calvert (1964) and Taylor and Silberston (1973) observe that about 50\% of all licensing contracts specify royalties only. Also, Lafontaine and Shaw (1999) show that, on average, franchise fees amount to no more than $8 \%$ of actual payouts from franchise holders to franchisees.

${ }^{15}$ See Tirole (1988, ch. 10.8) for a review of the literature on licensing.
} 
off the monopoly for a fixed fee and charge no royalty. ${ }^{16}$ In that case, the principal does not want competition downstream. When fixed lump-sum fees are not feasible, the patent holder must make her income through royalties. But then the double marginalization problem bites, and controlling market power downstream becomes an issue. Our result implies that decreasing marginal revenue is sufficient for a Demsetz auction (ex ante competition) to be better than ex post competition when ex post market structure is uncertain.

One could argue that an exclusive contract with a two part tariff is enough to prevent the double marginalization problem. Note, however, that to choose the right fixed fee the principal must know the demand curve. Our analysis implies that when marginal revenue is decreasing in quantities a joint franchise solves the problem.

\subsection{Dealerships}

Dealerships are similar to licensing, except for the fact that the principal's cost increases with the number of units sold. For example, consider the case of car dealerships. Cars are provided by the manufacturer at a fixed price and the dealers are free (within limits set by list price of the manufacturer) to bargain their markup with clients. The question for the manufacturer then is whether to have dealerships that are, say, spatially close and thus compete with each other, or to have one dealer with a cap on the resale price. ${ }^{17}$

Assume that $\tilde{c}(q)$ is the principal's cost function, with $\tilde{c}^{\prime}, \tilde{c}^{\prime \prime}>0$. Then $\mathcal{S}(p)=t D(p)-\tilde{c}(D(p))$, and, as with licensing, $\pi(p)=\frac{1}{2}(p-t) D(p)-c(D(p) / 2)$. Then: ${ }^{18}$

$$
\begin{aligned}
\mathcal{S}^{\prime} & =\left(t-\tilde{c}^{\prime}\right) D^{\prime} \\
\mathcal{S}^{\prime \prime} & =\left(t-\tilde{c}^{\prime}\right) D^{\prime \prime}-\left(D^{\prime}\right)^{2} \tilde{c}^{\prime \prime}
\end{aligned}
$$

and

$$
\begin{aligned}
\pi^{\prime} & =\frac{1}{2}\left[D+\left(p-t-c^{\prime}\right) D^{\prime}\right] \\
\pi^{\prime \prime} & =\frac{1}{2}\left[D^{\prime}+\left(1-\frac{c^{\prime \prime} D^{\prime}}{2}\right) D^{\prime}+\left(p-t-c^{\prime}\right) D^{\prime \prime}\right]
\end{aligned}
$$

We now show that $2 P^{\prime}+q P^{\prime \prime}<0$ is again sufficient for $W_{J}>W_{S}$. As before, since $\pi^{\prime}>0$ for all $p \in\left[\underline{p}, p_{m}\right)$, it follows, after some straightforward but tedious algebra, that $\mathcal{S}^{\prime \prime} \pi^{\prime}<\mathcal{S}^{\prime} \pi^{\prime \prime}$ for all $p \in\left[\underline{p}, p_{m}\right)$ is equivalent to

$$
D D^{\prime \prime}-2\left(D^{\prime}\right)^{2}<2 \pi^{\prime} \frac{\left(D^{\prime}\right)^{2} \tilde{c}^{\prime \prime}}{\left(t-\tilde{c}^{\prime}\right)}-\frac{1}{2}\left(D^{\prime}\right)^{3} c^{\prime \prime}
$$

which holds because the right hand side is (obviously) positive, while the left hand side is negative because

\footnotetext{
${ }^{16}$ See Gallini (1984) and Katz and Shapiro (1985).

${ }^{17}$ We abstract from other important considerations in these contracts, such as service quality.

${ }^{18}$ Note that royalties corresponds to the case where $\tilde{c} \equiv 0$.
} 
of Lemma 2.

\subsection{The social planner}

Next, we consider the case of a social planner who wants to contract for the provision of a service. As an example, consider highway franchises. In many developing countries roads are being franchised to private firms. In exchange for toll revenue, the franchise holder finances, builds, operates and maintains the road. ${ }^{19}$ In some cases roads are natural monopolies, and are awarded to the firm offering to charge the lowest toll. Nevertheless, when there is more than one way to get from one point to another, as is often the case in large cities, different roads could be awarded to different franchise holders. ${ }^{20}$ Should the regulator award all franchises to the same firm or award several highway franchises and let them compete? Another example is the auction of the rights to provide local telephony in rural areas, where the auction is based on the price of a standard local call. Is it better to have a single company provide the service or would it be better to allocate two companies to the area?

In this case the principal cares about social surplus (i.e. consumer and producer surplus) so that $\mathcal{S}(p)=$ $\int_{p}^{\infty} D(s) d s+p D(p)-2 c\left(\frac{D(p)}{2}\right) ;$ and $\pi(p)=\frac{1}{2} p D(p)-c\left[\frac{D(p)}{2}\right]$. Then

$$
\begin{aligned}
\mathcal{S}^{\prime} & =\left(p-c^{\prime}\right) D^{\prime}, \\
\mathcal{S}^{\prime \prime} & =\left(p-c^{\prime}\right) D^{\prime \prime}+D^{\prime}-\frac{1}{2}\left(D^{\prime}\right)^{2} c^{\prime \prime},
\end{aligned}
$$

and $\pi^{\prime}, \pi^{\prime \prime}$ are the same as in the case of dealerships (with $t=0$ ). Condition (1) now leads to

$$
\frac{\left(p-c^{\prime}\right) D^{\prime \prime}+D^{\prime}-\frac{1}{2}\left(D^{\prime}\right)^{2} c^{\prime \prime}}{\left(p-c^{\prime}\right) D^{\prime}}>\frac{\left(p-c^{\prime}\right) D^{\prime \prime}+2 D^{\prime}-\frac{1}{2}\left(D^{\prime}\right)^{2} c^{\prime \prime}}{D+\left(p-c^{\prime}\right) D^{\prime}},
$$

which, after some algebra yields

$$
\left(p-c^{\prime}\right)\left[D D^{\prime \prime}-2\left(D^{\prime}\right)^{2}\right]<-2 \pi^{\prime} D^{\prime}+\frac{1}{2}\left(D^{\prime}\right)^{2} D c^{\prime \prime},
$$

which is the same condition as in the case of procurement. Hence, again decreasing marginal revenue is sufficient for $W_{J}>W_{S}$.

Finally, we present a concrete example which suggests that welfare gains may be important when using a Demsetz auction instead of separate auctions.

Example We use the notation and definitions from the preceding subsection and assume $D(p)=1-p$,

\footnotetext{
${ }^{19}$ See Engel, Fischer and Galetovic (2001b) for a discussion of highway franchising.

${ }^{20}$ One example is the La Dormida project in Chile, which would compete with Route 68, the highway that currently joins Chile's capital, Santiago, with the port of Valparaíso. The Ministry of Public Works weighed the benefits of joint and separate auctions.
} 
$c(q)=c_{0}$. We also assume that the separate and joint auction of both franchises dissipate all rents. ${ }^{21}$ Since $\mathcal{S}^{\prime}(p)=-D(p)=p-1$ and $\pi(p)=p(1-p)-c_{0}$, we have that $\pi^{\prime \prime} / \pi^{\prime}<\mathcal{S}^{\prime \prime} / \mathcal{S}^{\prime}$ if and only if $-2 /(1-2 p)<$ $-1 /(1-p)$ for all $p<p_{m}=1 / 2$, which indeed holds. It follows that the sufficient condition for Proposition 2 is satisfied.

Assume that the ex-ante distribution of market structure outcomes in the case of separate franchises $F$ is a point distribution with weights of $1 / 2$ on collusion at the bid price and $1 / 2$ on price competition with price equal to marginal cost (zero). Then $p_{J}$ is the smallest solution to $p(1-p)=c_{0}$ while $p_{S}$ is the smallest solution to $\frac{1}{2} p(1-p)=c_{0}$. The existence of a solution in both cases requires $c_{0}<1 / 8$. Then:

$$
W_{J}-W_{S}=\frac{1}{2}\left(1-p_{J}\right)^{2}-\frac{1}{4}\left\{\left(1-p_{S}\right)^{2}+1\right\}=\frac{1}{8}\left[2 \sqrt{1-4 c_{0}}-1-\sqrt{1-8 c_{0}}\right]>0, \quad \forall c_{0}>0,
$$

Furthermore, in this example a joint auction can lead to a welfare increase of as much as $17 \%$.

\section{Conclusion}

We have shown a simple condition for a principal to prefer to contract the provision of a good from a single agent via a Demsetz auction, rather than by having multiple agents provide the good under (imperfectly) competitive conditions. In the canonical cases of procurement, royalty contracts and dealerships, decreasing marginal revenue ensures that a Demsetz auction (ex ante competition) is better for the principal than ex post competition. This result is surprising, because it is independent of the expected intensity of ex post competition.

The results in this paper do not necessarily imply an endorsement of monopolies, since many relevant factors were left out of our analysis. First, we assumed a single service quality, which can be verified at no cost, even though in most cases quality will be worse in the absence of competition. Second, we ignored political economy and asymmetric information considerations, which may be worse when a regulator deals with a monopoly. Third, we rule out incomplete contracting and the hold-up problem. For example, a manufacturer might prefer to have competing dealers in order to avoid a bilateral monopoly. Finally, we have not considered the possibility of technical change in the delivery of franchise services, a factor that if present makes competition more desirable if it accelerates the introduction of new technologies.

On the other hand, there are some aspects we left out which strengthen the case for a joint auction. First, if agents are risk averse, the preference for joint auctions increases. More importantly, we have assumed that a joint contract does not lead to any cost savings; or, conversely, that ex post competition, which implies more than one agent, does not lead to (fixed) cost duplication. A common concern when formerly monopolistic markets are liberalized is that competition may lead to inefficient cost duplication through "excessive" entry. ${ }^{22}$ With a Demsetz auction, however, cost duplication is no longer an issue. Our result

\footnotetext{
${ }^{21}$ Thus the common value of both expressions in Condition 1 is zero.

${ }^{22}$ See, for example, Armstrong (2000).
} 
indicates that an exclusive contract may be preferable even when it does not prevent fixed-cost duplication. 


\section{Appendix}

\section{A Proof of Proposition 2}

Differentiating both sides of $\pi \circ \pi^{-1}(p)=p$ leads to:

$$
\left(\pi^{-1}\right)^{\prime}(p)=\frac{1}{\pi^{\prime}\left(\pi^{-1}(p)\right)} .
$$

Hence:

$$
\left(\mathcal{S} \circ \pi^{-1}\right)^{\prime}(p)=\mathcal{S}^{\prime}\left(\pi^{-1}(p)\right)\left(\pi^{-1}\right)^{\prime}(p)=\frac{\mathcal{S}^{\prime}\left(\pi^{-1}(p)\right)}{\pi^{\prime}\left(\pi^{-1}(p)\right)} .
$$

Differentiating both sides of (8) with respect to $p$ and using (9) leads to:

$$
\left(\mathcal{S} \circ \pi^{-1}\right)^{\prime \prime}(p)=\frac{\mathcal{S}^{\prime \prime} \pi^{\prime}-\mathcal{S}^{\prime} \pi^{\prime \prime}}{\left(\pi^{\prime}\right)^{3}}
$$

where all terms on the r.h.s. are evaluated at $\pi^{-1}(p)$. Since $\pi^{\prime}>0$ this implies that $S \circ \pi^{-1}$ is concave if and only if $\mathcal{S}^{\prime \prime} \pi^{\prime}<\mathcal{S}^{\prime} \pi^{\prime \prime}$. And since $\mathcal{S}^{\prime}<0$ and $\pi^{\prime}>0$ we conclude that $\pi^{\prime \prime} / \pi^{\prime}<\mathcal{S}^{\prime \prime} / \mathcal{S}^{\prime}$ is necessary and sufficient for concavity of $\mathcal{S} \circ \pi^{-1}$. The result now follows.

\section{B Proof of Lemma 2}

To prove (i) and (ii) totally differentiate the identity $q \equiv D[P(q)]$ with respect to $q$ to obtain

$$
1=D^{\prime} P^{\prime}
$$

from which (i) follows. Next, totally differentiate $P^{\prime}(q) \equiv \frac{1}{D^{\prime}[P(q)]}$ with respect to $q$ to obtain

$$
P^{\prime \prime}=-\frac{D^{\prime \prime}}{\left(D^{\prime}\right)^{2}} P^{\prime}
$$

from which (ii) follows by substituting $\frac{1}{D^{\prime}}$ for $P^{\prime}$. The proof of (iii) and (iv) is analogous and we omit it.

\section{Proof of Lemma 3}

Proof: Sufficiency: use (i) and (ii) in Lemma 1 to substitute for $P^{\prime}$ and $P^{\prime \prime}$. Necessity: use (iii) and (iv) to substitute for $D, D^{\prime}$ and $D^{\prime \prime}$. 


\section{References}

[1] Armstrong, M., "Regulation and inefficient entry", mimeo, Nuffield College, Oxford, 2000.

[2] Caillaud, B., and J. Tirole, "Essential Facility Financing and Market Structure," Mimeo, IDEI, U. of Toulouse, 2001

[3] Calvert, R., The Encyclopedia of Patent Practice and Invention Management. New York: Reinhold, 1964

[4] Chadwick, E., "Results of Different Principles of Regulation in Europe," Journal of the Royal Statistical Society, Series A22, 381-420, 1859

[5] Demsetzx, H., "Why Regulate Utilities," Journal of Law and Economics, 11, 55-66, 1968

[6] Engel, E., R. Fischer and A. Galetovic, "How to Auction an Essential Facility when Underhand Agreements are Possible,” NBER Working Paper \#8146, 2001a

[7] Engel, E., R. Fischer and A. Galetovic, "Least-Present-Value-of-Revenue Auctions and Highway Franchises," Journal of Political Economy, 109, 993-1020, 2001b

[8] Gallini, N. "Deterrence Through Market Sharing: A Strategic Incentive for Licencing," American Economic Review 74, 931-941, 1984

[9] Harstad, R. and M. Crew, "Franchise Bidding Without Holdups: Utility Regulation with Efficient Pricing and Choice of Provider," Journal of Regulatory Economics 15, 141-163, 1999

[10] Katz, M. and C. Shapiro, "On the Licencing of Innovations," Rand Journal of Economics 16 504-520, 1985

[11] Laffont, J. y J. Tirole, A Theory of Incentives in Procurement and Regulation. Cambridge, MIT Press, 1993

[12] Lafontaine F. and K. Shaw, "The Dynamics of Franchise Contracting: Evidence from Panel Data", Journal of Political Economy 107, 1041-1080, 1999.

[13] Posner, R., "The Appropriate Scope for Regulation in Cable Television," Bell Journal of Economics 3, $335-358,1972$

[14] Pratt, J., "Risk Aversion in the Small and in the Large," Econometrica 32, 122-136, 1964

[15] Riordan, M. and Sappington, D. "Awarding Monopoly Franchises," American Economic Review 77, $375-387,1987$ 
[16] Spengler, J., "Vertical Integration and Anti-Trust Policy," Journal of Political Economy 58, 347-352, 1950

[17] Spulber, D., Regulation and Markets. Cambridge: MIT Press, 1989

[18] Stigler, G., The Organization of Industry. Homewood: Richard D. Irwin, 1968

[19] Taylor, C. and Z. Silberston, Economic Impact of Patents, Cambridge: Cambridge University Press, 1973

[20] Tirole, J., The Theory of Industrial Organization. Cambridge: MIT Press, 1988

[21] Williamson, O., Markets and Hierarchies. New York: Free Press, 1975 